\title{
INFLUENCE OF W ON THE TEMPORAL EVOLUTION OF THE MICROSTRUCTURE OF A Ni-AI-Cr SUPERALLOY ON A NANOSCALE
}

\author{
C. K. Sudbrack*, D. Isheim*, R. D. Noebe**, and D. N. Seidman* \\ * Materials Science and Engineering Department, Northwestern University, Evanston, IL 60208 \\ ** NASA Glenn Research Center, Cleveland, Ohio 44135
}

Due to the properties of native oxides of $\mathrm{Cr}$ and $\mathrm{Al}, \mathrm{Ni}-\mathrm{Al}-\mathrm{Cr}$ base alloys have inherently good oxidation and corrosion resistance, and are among the most popular Ni-based superalloys. Their excellent mechanical properties are a direct consequence of the presence of $\mathrm{L}_{2}$-ordered precipitates of $\mathrm{Ni}_{3} \mathrm{Al}\left(\gamma^{\prime}\right)$ in a $\mathrm{Cr}$-rich $\mathrm{Ni}$-Al solid-solution $(\gamma)$. Employing three-dimensional atom-probe (3DAP) microscopy and kinetic Monte Carlo simulations, Schmuck et al. investigated the temporal evolution of $\gamma^{\prime}$-precipitates in a $\mathrm{Ni}-\mathrm{Al}-\mathrm{Cr}$ alloy, with a low supersaturation of $\mathrm{Al}$ [1]. In this article, we report on the alloys $\mathrm{Ni}-10 \mathrm{Al}-8.5 \mathrm{Cr}$ (at. \%) and Ni-10 Al-8.5 Cr-2 W (at. \%), which have a high Al supersaturation, using 3DAP microscopy. Cast ingots are homogenized at $1300^{\circ} \mathrm{C}$ for $20 \mathrm{~h}$ and for $0.5 \mathrm{~h}$ about $50^{\circ} \mathrm{C}$ above the solvus temperature. We present results for: (a) water-quenched; (b) 0.25 $\mathrm{h}$ at $800^{\circ} \mathrm{C}$; and (c) $264 \mathrm{~h}$ at $800^{\circ} \mathrm{C}$ aging states. From $3 \mathrm{D}$ atom-by-atom reconstructions, the elemental partitioning ratios and spatially resolved concentration gradients across $\gamma$ ' precipitates are obtained.

Spheriodal $\gamma^{\prime}$ precipitates 5-20 nm in size form during quenching in both Ni-10 Al-8.5 Cr and Ni-10 Al-8.5 Cr-2W (Fig. 1) and have a high number density $\left(\sim 10^{23} \mathrm{~m}^{-3}\right)$. After $0.25 \mathrm{~h}$ aging, the precipitates remain spheriodal in contrast to the $264 \mathrm{~h}$ aging state, which contain cuboidal precipitates. A decrease from $228 \mathrm{~nm}$ to $154 \mathrm{~nm}$ in average cube length results from the $\mathrm{W}$ addition indicating a reduction in the coarsening rate. In Fig. 1, the elemental distributions demonstrate that $\mathrm{Al}$ and $\mathrm{W}$ partition to $\gamma^{\prime}$, and $\mathrm{Cr}$ to $\gamma$. Elemental partitioning is quantified by the ratio of the precipitate concentration to the matrix concentration. The significant decrease resulting from the $\mathrm{W}$ addition in chromium's ratio for all aging states (Fig. 2) indicates that the W causes a stronger partitioning of $\mathrm{Cr}$ to $\gamma$, and may be a driving force for this result. However, $\mathrm{W}$ has only a small effect on the partitioning of $\mathrm{Al}$ and Ni. Partitioning of $\mathrm{W}$ increases with aging, and evolves more slowly than Al, which has the largest diffusivity in this alloy. Proxigram concentration profiles [2] obtained from the 3DAP analyses (Figs. 3 and 4) present, on a nanoscale, spatially resolved concentration gradients across the $\gamma / \gamma^{\prime}$ interface. For the as-quenched state of Ni-10 Al- 8.5 Cr, the proxigram in Fig. 3a shows a gradual decrease of $\mathrm{Cr}$ across the $\gamma / \gamma^{\prime}$ interface. In contrast to the aged states, whose $\mathrm{Cr}$ profiles are characterized by a sharp rise at the $\gamma / \gamma^{\prime}$ interface (Figs. 3b, 3c), clear partitioning of $\mathrm{Cr}$ occurs. Unlike the ternary alloy, clear $\mathrm{Cr}$ partitioning to $\gamma$ is already present in the as-quenched state of Ni-10 Al-8.5 Cr-2W (Fig 4a). In the as-quenched and $0.25 \mathrm{~h}$ aging states, a concentration gradient of $\mathrm{W}$ exists within $\gamma^{\prime}$ (note arrowheads in Fig. 4). The influence of $\mathrm{W}$ on the chemistry of evolving $\gamma^{\prime}$ precipitates for $\mathrm{Ni}-10 \mathrm{Al}-8.5 \mathrm{Cr}$ is presented [3].

[1] C. Schmuck, P. Caron, A. Hauet, and D. Blavette, Phil. Mag. A 76, 527-542 (1997).

[2] O. C. Hellman, J. A. Vandenbroucke, J. Rüsing, D. Isheim, and D. N. Seidman, Microsc. Microanal. 6, 437-444 (2000).

[3] This research is supported by National Science Foundation DMR-972896 (CKS, DI \& DNS) and NASA Glenn HOTPC (RDN). 


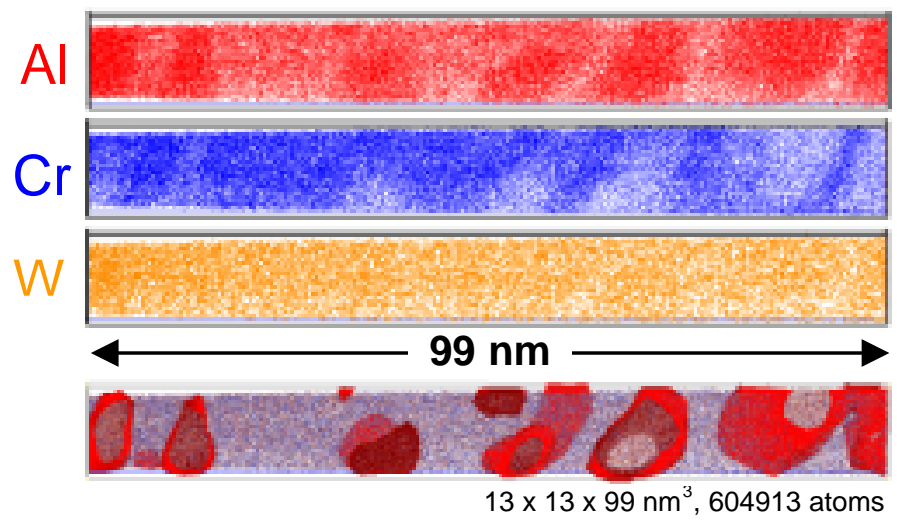

FIG. 1 - Three-dimensional distributions of $\mathrm{Al}, \mathrm{Cr}$ and $\mathrm{W}$ atoms for as-quenched Ni-10 Al-8.5 Cr-2 W (at. \%) showing elemental partitioning behavior to $\gamma$ or $\gamma^{\prime} .12$ at.\% $\mathrm{Al}$ isoconcentration surface in red reveals $\gamma^{\prime}$ precipitates with sizes $5-20 \mathrm{~nm}$ (bottom).

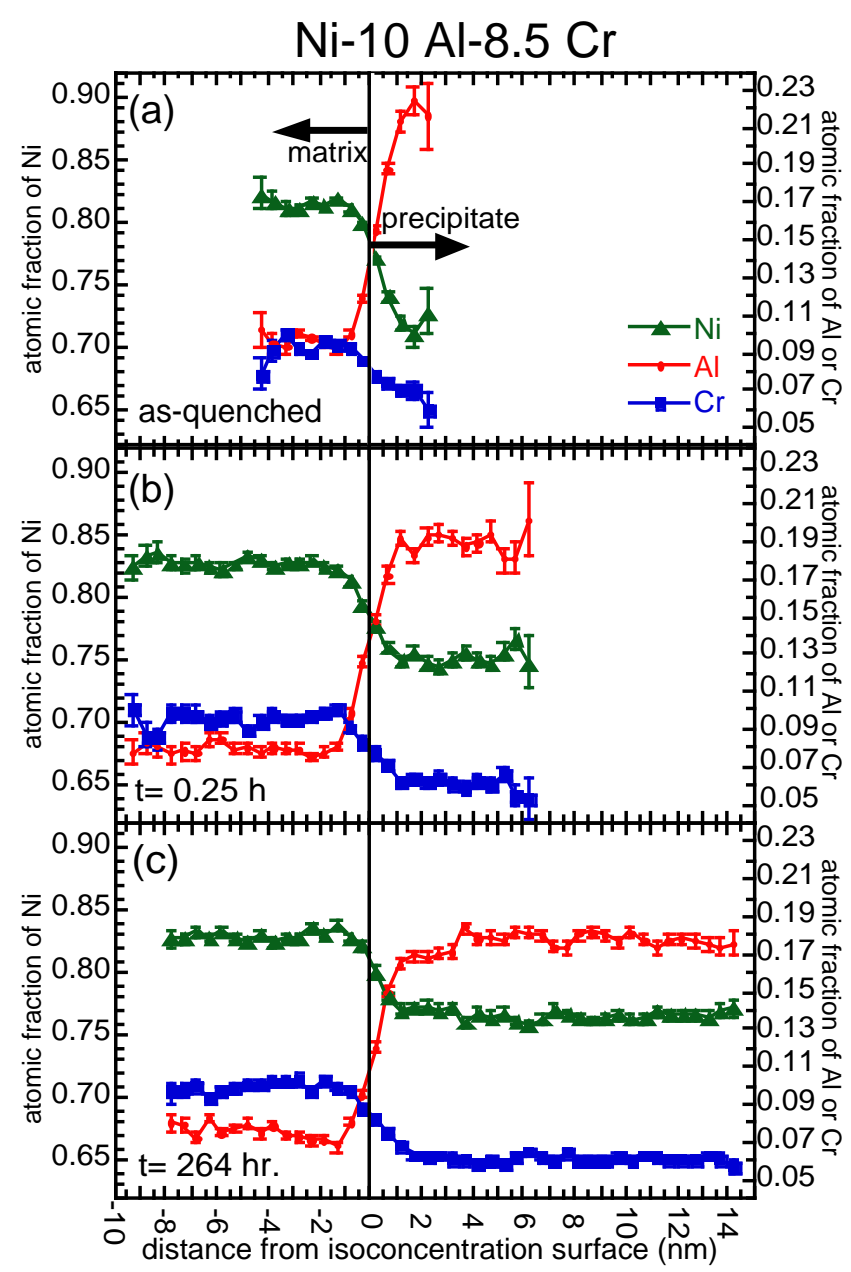

FIG. 3 - Proxigram concentration profiles across matrix-precipitate interfaces of the $\gamma^{\prime}$ precipitates in Ni-10 Al-8.5 Cr (at. \%) after (a) quenching, after (b) aging for $0.25 \mathrm{~h}$ and (c) $264 \mathrm{~h}$ at $800^{\circ} \mathrm{C}$.

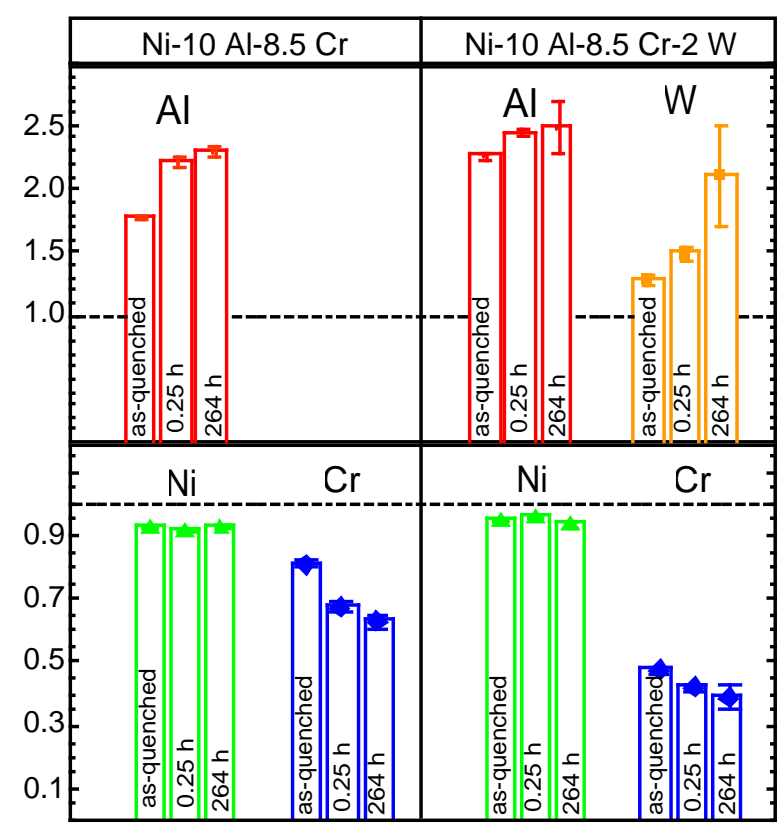

FIG. 2 - Partitioning ratios measured by 3DAP microscopy analyses of Ni-10 Al-8.5 Cr (left) and $\mathrm{Ni}-10 \mathrm{Al}-8.5 \mathrm{Cr}-2 \mathrm{~W}($ right $)$ as a function of aging time- as-quenched, $0.25 \mathrm{~h}$ and $264 \mathrm{~h}$ at $800^{\circ} \mathrm{C}$.

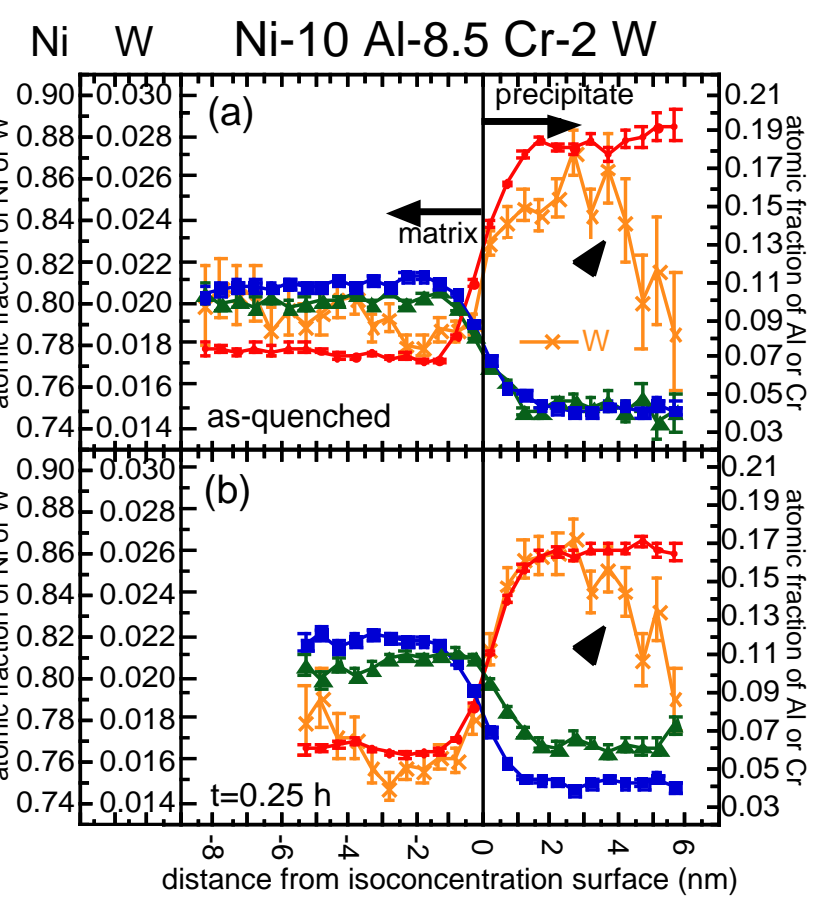

FIG. 4 - Proxigram concentration profiles across matrix-precipitate interfaces of the $\gamma^{\prime}$ precipitates in Ni-10 Al-8.5 Cr-2 W (at. \%) after (a) quenching and (b) aging for $0.25 \mathrm{~h}$ at $800^{\circ} \mathrm{C}$. 